\title{
THE QUORUM SENSING AND THE NODULATION COMPETITIVENESS OF Rhizobia DURING INFECTION OF LEGUMINOUS PLANTS
}

\author{
N.I. Vorobyov, N.A. Provorov
}

All-Russian Research Institute for Agricultural Microbiology, Federal Agency of Scientific Organizations, 3, sh. Podbel'skogo, St. Petersburg, 196608 Russia, e-mail vorobyov@arriam.spb.ru Acknowledgements:

Supported by Russian Science Foundation (project № 14-26-00094)

Received March 24, 2015

\section{Abstract}

A basic property of Rhizobia is the ability to compete for nodule formation under a multi strain inoculation. Its regulation remains poorly understood, thus limiting advances in biotechnological studies to improve the effectiveness of Rhizobia microbial preparations. The mathematical model of Rhizobia Nodulation Competitiveness (RNC) for describing a multi strains inoculation of leguminous plants is created (RNC-model). In the RNC-model we took into account that under Quorum Sensing regulation (QS-regulation) in soil niches not only the bacteria number in the niche, but a cell's migration into adjacent niches is limited. The RNC-model represents a powerlaw nonlinear dependence of cell's migration from a niche from the cell's spatial density in the niche (the power value is less than 1). According to the formula of the RNC-model, the relative proportion of migratory cells from niche habitat decreases under increasing cell's density. We suggest that after a multi strains inoculation in the rhizosphere of plants the bacterial strains with a large cells migration flow from the niche habitat (with big RNC) will be presented in large amounts. The verification and parametric identification (migration activity of strains, the index of frequency-dependent selection) of the RNC-model were carried out with using the previously published experimental data. The analysis of RNC-model's parameters, calculated with using these data, showed that rizobia strains with a large migratory activity and a small index of frequency-dependent selection form a large migratory flow of cells from the niche habitat and demonstrate large RNC. The genetic modification of rhizobia with the aim of improving the RNC may cause the intensification of migration flows of strain cells from the niche habitat and the accelerated spending of niche resources. The intensive migration of cells from soil niche may lead to premature consumption of niche's resource and cause a cell death of rhizobia before they form symbiosis with legume plants. The considered features of survival and migration of rhizobia in natural soil conditions must be considered, especially, in the development of microbial preparations with prolonged action.

Keywords: mathematical models, Rhizobia, nodulation competitiveness, Quorum Sensing regulation, migration, frequency-dependent selection.

The basic symbiotic property of rhizobia is their ability to compete for nodule formation in legumes under multistrain inoculation (Rhizobia Nodulation Competitiveness - RNC). Molecular genetic studies have revealed polygenic RNC control and demonstrated its relationship with various cultural biochemical and symbiotic characteristics (the structure of cellular wall, resistance to antibiotics and phages, ability to be adsorbed on root surface, the rate of nodule formation under plant monoinoculation) and made it possible to proceed to the development of methods of construction of rhizobia strains with increased RNC [1-5]. Its regulation remains poorly understood, thus limiting biotechnological studies advances to improve the effectiveness of rhizobia microbial preparations.

Earlier, a hypothesis was proposed suggesting that the rate of bacteria migration between different niches determining their competitiveness can be regulated by the mechanism of Quorum Sensing (QS-regulation) [6-8]. This is confirmed by experimental data on plant nodule colonization by rhizobia [9, 10] demonstrating a nonlinear dependence of the total number of bacteria $\mathrm{RNC}$ 
(hence, the spatial density) in the inoculum. QS-regulation is performed by lowmolecular signaling molecules (autoinducers) that are released by bacteria into environment and affect regulatory proteins which causes the blockage of cell division [11-16]. As a result, a population can be divided into groups of cells of different physiological condition with activated or blocked reproduction [17]. Previously, this differentiation has been shown in alfalfa (Sinorhizobium meliloti) nodule bacteria in which QS-regulation provides the distinction of isogenic cells by the exopolysaccharides biosynthesis gene activity, which determines the rate of the colony development [18].

The purpose of the present study was to construct a mathematical model of strain Nodulation Competitiveness (RNC) taking into account the QS-regulation of cell migration flows from the inoculum into nodule niches of leguminous plants.

Model construction. The ratio of the proportion of nodules colonized by two competing strains $\left(k_{1}: k_{2}\right)$ has been previously found to be associated with the ratio of their numbers in the inoculum volume unit $\left(N_{1}: N_{2}\right)$ by the following equation:

$$
\log \left(\frac{k_{1}}{k_{2}}\right)=\log \left(\mathrm{c}_{12}\right)+\mathrm{a} \cdot \log \left(\frac{N_{1}}{N_{2}}\right),
$$

where $k_{1}+k_{2}=1 ; \mathrm{c}_{12}>0$ is a pair RNC index equal to the ratio of nodules colonized by strains studied at their equal representation in the inoculum $\left(\mathrm{c}_{12}=k_{1}: k_{2}, N_{1}=N_{2}\right) ; 0<\mathrm{a}<1$ is an index of frequency dependent selection (FDS) which determines the selective advantage of the most rare strain when $\mathrm{c}_{12}=1$. With the decrease in the FDS index, representation of this strain in the nodules increases [11].

We believe that in response to the increasing spatial density of each strain, QS-regulation, which is maintaining the ratio of dividing and resting cells, shifts it to the advantage of resting cells which causes a slowdown in the strain growth rate. In the simulation process, we assumed that cell migration flows from the habitat niche were exposed to QS-regulation and depended nonlinearly on the spatial population density. These assumptions seem logical since dividing cells consume significantly more energy received from outside than resting cells that need the resources just to maintain their viability. It is obvious that in order to save resources and increase the bacterial strain survival, the proportion of its active cells should be minimal. It is possible that QS-regulation was formed in bacterial populations for the purpose of their long-term survival under the conditions of external resource deficiency.

The intensity of QS-regulated migration flow of bacterial strain from the inoculum determines the extent of cell accumulation on the root surface. In turn, the difference in the number of cells on the root surface determines the distribution of strains in the nodules in their colonization. Therefore, the primary cause of bacterial strain RNC is the QS-regulation of cell migration flows. Therefore, when constructing the RNC model, we will consider the QSregulation of cell migration flows the functional character of which is presented in the equation (1). Since in response to an increase in spatial density of each strain, QS-regulation reduces the proportion of migrating cells, the inverse proportionality of the migration index $(\mathrm{m})$ to the number of each strain cells should be used in the RNC model:

$$
m=\frac{n_{\mathrm{M}}}{N}=\left[1+\left(\frac{N}{\mathrm{~N}_{\mathrm{M}}}\right)^{1-\mathrm{a}}\right]^{-1},
$$


where $N$ is the total number of dividing and resting strain cells per the inoculum volume unit; $n_{\mathrm{M}} \leq N$ is the number of cell capable of migration; $\mathrm{N}_{\mathrm{M}}$ is a bacterial strain migration activity expressed as cell density in the niche at which one half of cells are capable of migration into adjacent niches $\left(2 \cdot n_{\mathrm{M}}=N=\mathrm{N}_{\mathrm{M}}\right) ; 0<\mathrm{a}<1$ is FDS index from the equation (1).

With multi strain competition, to calculate the proportion of nodules $\left(k_{J}\right)$ colonized by $J$-strain, it is necessary to determine the proportion of this strain $\left(n_{\mathrm{M} J}\right)$ among the migrating cells of all strains:

$$
k_{J}=n_{\mathrm{M} J} / \sum_{L=1}^{\mathrm{S}} n_{\mathrm{M} L},
$$

where $k_{J}$ is proportion of nodules colonized by $J$-strain; $n_{\mathrm{M} J}, n_{\mathrm{M} L}$ are numbers of $J$ - and $L$-strain cells per the inoculum volume unit calculated by the RNC model (2); $\mathrm{S}$ is the number of strains involved in nodule colonization. The following equation can be obtained from (3) for the competition between two strains:

$$
k_{1}: k_{2}=n_{\mathrm{M} 1}: n_{\mathrm{M} 2} \cdot
$$

Inserting (2) into (4) and considering that $N_{1}$ и $N_{2}$ are taken much greater than $\mathrm{N}_{\mathrm{M} 1}$ and $\mathrm{N}_{\mathrm{M} 2}$, an asymptotically close to (1) equation can be obtained:

$$
\log \left(\frac{k_{1}}{k_{2}}\right)=\log \left(\frac{n_{\mathrm{A} 1}}{n_{\mathrm{A} 2}}\right)=\log \left(\frac{N_{\mathrm{M} 1}^{1-\mathrm{a}_{1}}}{N_{\mathrm{M} 2}^{1-\mathrm{a}_{2}}}\right)+\log \left(\frac{N_{1}^{\mathrm{a}_{1}}}{N_{2}^{\mathrm{a}_{2}}}\right),
$$

where $\mathrm{N}_{\mathrm{M} 1}, \mathrm{~N}_{\mathrm{M} 2}$ are migration activity of the populations of competing strains; $0<\mathrm{a}_{1}, \mathrm{a}_{2}<1$ are FDS indices of these strains. Asymptotic proximity of (1) and (5) proves the correctness of the RNC model (2) and enables the use of (2) and (3) to describe the multistrain colonization of legume roots. As a result, individual $\left(\mathrm{c}_{1}=N_{\mathrm{M} 1}^{1-\mathrm{a}_{1}}, \mathrm{c}_{2}=N_{\mathrm{M} 2}^{1-\mathrm{a}_{2}}\right)$ and pair $\left(\mathrm{c}_{12}=\mathrm{c}_{1}: \mathrm{c}_{2}\right)$ RNC indices can be calculated for two competing strains.

Model verification. Using experimental data $[9,10]$, we determined the levels of migration activity of populations and the individual RNC and FDS indices for competing rhizobia strains (Table). Determination coefficient $\left(\mathrm{r}^{2}\right)$ for experimental and theoretical (calculated according to the model) data was used as the indicator of the RNC model adequacy. Proximity of determination coefficient to one confirms the high convergence of the RNC model and the experimental data (see Table and Fig.).

Analytical regularities constructed using the RNC models for parameter values from the Table demonstrated the increase in the number of migrating cells with an increase in the density of bacteria in the inoculum (see Fig., A, solid lines), and the decrease in the proportion of migrating cells (migration index) (see Fig., A, dotted lines). For strain KIM5s (see Fig. B), at the density in the inoculum of $10^{8}$ cells $/ \mathrm{ml}$ and $10^{10}$ cells $/ \mathrm{ml}$, QS-regulation of the migrating cells flow is determined by the values of 2600 and 9300 cells $/ \mathrm{ml}$, respectively.

\begin{tabular}{|c|c|c|c|c|}
\hline $\begin{array}{l}\text { Rhizobia } \\
\text { strain }\end{array}$ & $\begin{array}{l}\text { Bacteria migration activity } \\
\mathrm{N}_{\mathrm{M}} \text {, cell } / \mathrm{ml}\end{array}$ & $\begin{array}{l}\text { Individual RNC } \\
\text { index, } \mathrm{c}_{\mathrm{M}}\end{array}$ & FDS index, $a_{M}$ & $\begin{array}{l}\text { Model determination } \\
\text { coefficient, } \mathrm{r}^{2}\end{array}$ \\
\hline FSS1 (9) & $10 \pm 1$ & $3.8 \pm 0.4$ & $0.42 \pm 0.03$ & 0.98 \\
\hline FH20S1 (9) & $9 \pm 1$ & $4.2 \pm 0.5$ & $0.35 \pm 0.03$ & 0.93 \\
\hline FS163S (9) & $12 \pm 1$ & $4.0 \pm 0.5$ & $0.45 \pm 0.03$ & 0.98 \\
\hline KIM5s (10) & $42 \pm 2$ & $14.8 \pm 1.6$ & $0.28 \pm 0.02$ & 0.98 \\
\hline CE3 (10) & $6 \pm 1$ & $3.5 \pm 0.6$ & $0.30 \pm 0.02$ & 0.98 \\
\hline
\end{tabular}

Parameters of the RNC model of legume nodule colonization by Rhizobium leguminosarum strains

In related strains KIM5s and CE3 (see Table), FDS indices are similar, 
therefore their equality of $a_{1}=a_{2}$ can be accepted in the equation (5). In this case, (5) is equal to (1) which confirms the correctness of the RNC model (2). If the strain FSS1 inoculum (see Table) contains $10^{7}$ cells $/ \mathrm{ml}$, and the strain FH20S1 inoculum contains $10^{5}$ cells $/ \mathrm{ml}\left(N_{1}: N_{2}=100: 1\right)$, these strains will be present in nodules in a ratio of $k_{1}: k_{2}=93: 7$, that is the representation of the rare FH20S1 strain of nodules increases 7 times. A further FDS index reduction $\left(a_{1}=0.210, a_{2}=0.175\right)$ will change the ratio to the benefit of the nodule strain FSS1 still more $\left(k_{1}: k_{2}=80: 20\right)$.

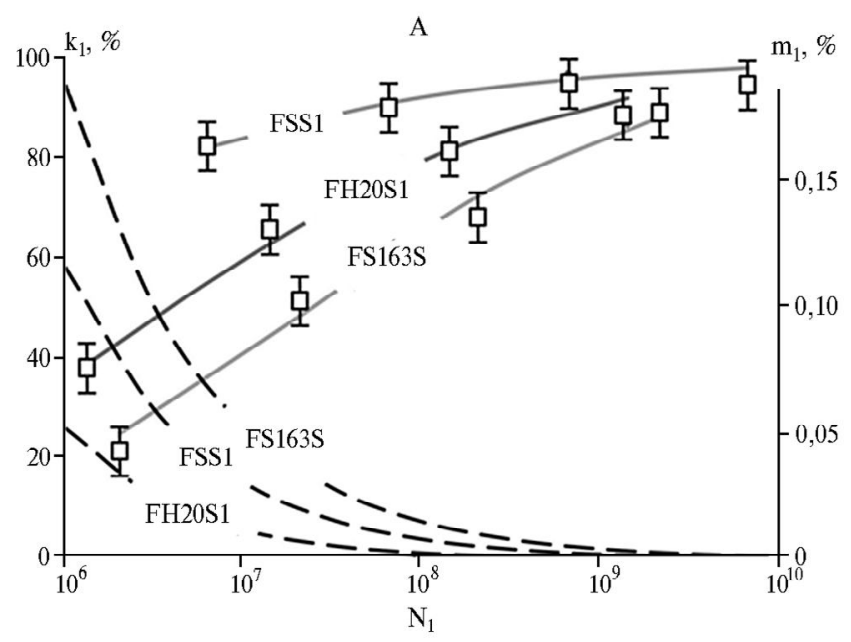

Distribution of competing rhizobia strains in the nodules of leguminous plants depending on the density of cells in the inoculum $\left(\mathrm{N}_{1}, \mathrm{~N}_{2}\right)$ : $k_{1}-$ proportion of nodules formed by strain FSS1 [9]. Left axes refer to experimental data (号) and the solid lines constructed by the RNC model (2), right axes refer to dotted lines which correspond to migration index $m_{1}(\mathrm{~A})$ and pair $\mathrm{RNC}$ index $\mathrm{c}_{12}$ (B) calculated by the RNC model for strain FSS1.

A. Results of strain Rhizobium leguminosarum bv. viciae (FSS1, FH20S1, FS163S) and local soil population com-

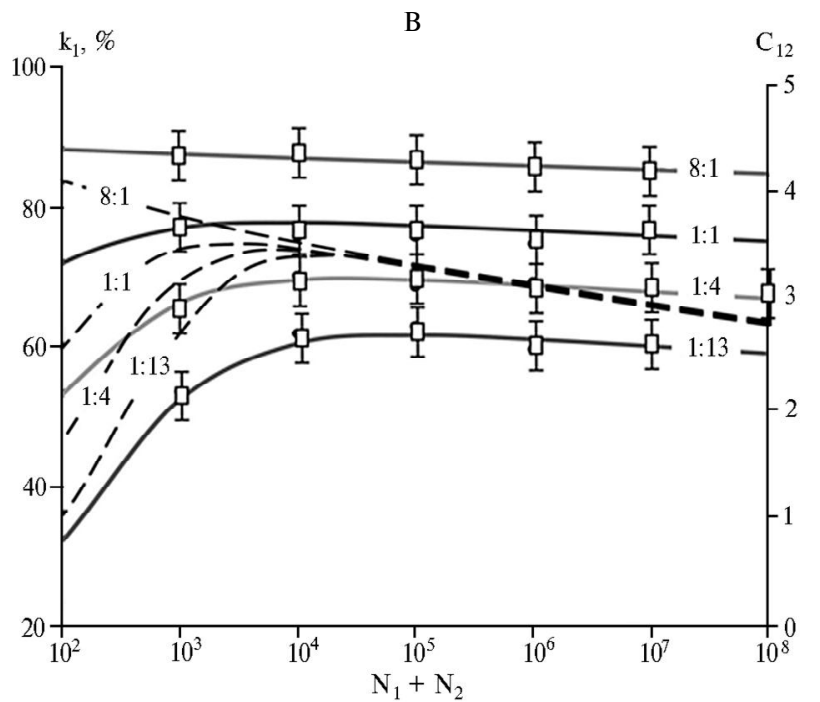
petition for horse bean Vicia faba var. Ascott nodulation [9].

B. Results of mutant strain KIM5s and $R$. leguminosarum bv. Phaseoli parent strain CE3 competition for common bean Phaseolus vulgaris var. Puebla 152 nodulation at various KIM5s:CE3 ratio in inoculum [10].

As it is evident from the data in the Table, the KIM5s strain has the highest individual $\mathrm{RNC}$ index $\left(\mathrm{c}_{4}=14.8\right)$. QS-regulation of this strain number can be assumed to support the greater flow rate of migrating cells compared with that of strain CE3 $\left(c_{5}=3.5\right)$. Therefore, in equal proportions of strains KIM5s and CE3 in inoculum, strain KIM5s will be mainly represented in nodules: $k_{4}: k_{5}=\mathrm{c}_{45}=\mathrm{c}_{4}: \mathrm{c}_{5}=14.8: 3.5=4.2>1$. Thus, the increased individual RNC index and the low level of migration activity can be attributed to the weakened QS-regulation of bacteria migration flow from the inoculum.

The analysis of revealed regularities suggests that bacterial strains with high migration activity index and individual RNC index spend more energy for cell migration which reduces the survival period of bacteria. Therefore, genetic modification of strains with the aim of improving the RNC may result in a decrease in rhizobia viability outside the plant and their subsequent death. 
Rhizobia strains with improved efficiency of symbiotic $\mathrm{N}_{2}$-fixation are known for their low survival rate [19]. Therefore, FDS to the benefit of rare strains can play an important role in maintaining effective bacteria and plant interaction. With this selection, predominant reproduction of active nitrogen fixers takes place in the nodules providing maximum productivity of the Rhizobium-legume system.

Earlier, studies of phytoparasite systems have shown that plants can affect the QS-regulation of virulence genes of pathogenic bacteria thus inhibiting the infectious process [20]. The similar mechanism is possible in the formation of a Rhizobium-legume symbiosis, which makes it possible for the plant to regulate the flow of bacteria from the environment into endosymbiotic niches and thus carry out the selection of rhizobia strains based on the symbiotic efficiency features. Verification of this hypothesis will be the scope of our future study.

Thus, rhizobian nodulation competitiveness (RNC) is determined not only by strain benefits at the development of nutrient resources in legume rhizosphere but also by the migration activity of the bacterial cell of habitat niches. The RNC increase by genetic engineering may cause the intensification of migration flows of rhizobia cells and the accelerated spending of soil resources of the niche, which the rhizobian population inhabits beyond the symbiosis. Therefore, at prolonged survival of bacteria in soil conditions, the increased energy spent for cell migration may increase the risks of population death. The features of survival and migration of rhizobia should be considered especially in the development of microbial preparations with prolonged action.

\section{RE F E R E N C ES}

1. K u r chak O.N., Provorov N.A., S i m a rov B.V. Genetika, 2001, 37(9): 1225-1232.

2. Onishchuk O.P., Kurchak O.N., Sharypova L.A., Provorov N.A., Simarov B.V. Genetika, 2001, 37(11): 1507-1512.

3. On is chuk O.P., S i m a rov B.V. Genetika, 1996, 32: 1157-1166.

4. O nish chuk O.P., S i m a rov B.V. Genetika, 1995, 31(3): 293-303.

5. Sessitsch A., Jje mba P.K., Hardarson G., Akkermans A.D.L., Wilson K.J. Measurement of the competitiveness index of Rhisobium tropici strain CIAT899 derivatives marked with the gusA gene. Soil Biol. Biochem., 1997, 29: 1099-1110.

6. Pérez-Montaño F., Jiménez-Guerrero I., D e l Cerro P., B aena-Ro pero I., Lypez-Baena F.J., Ollero F.J., Bellogín R., Lloret J., Espuny R. The symbiotic biofilm of Sinorhizobium fredii SMH12, necessary for successful colonization and symbiosis of Glycine max cv. Osumi, is regulated by Quorum Sensing systems and inducing flavonoids via NodD1. PLOS ONE, 2014, 9(8): e105901 (doi: 10.1371/journal.pone.0105901).

7. Jitacksorn S., S adowsky M.J. Nodulation gene regulation and Quorum Sensing control density-dependent suppression and restriction of nodulation in the Bradyrhizobium japonicum-soybean symbiosis. Appl. Environ. Microbiol., 2008, 74: 3749-3756 (doi: 10.1128/AEM.02939-07).

8. Zheng H., Zhong Z., Lai X., Chen W.X., Li S., Zhu J. LuxR/LuxI-type QuorumSensing system in plant bacterium Mesorhizobium tianshanense controls symbiotic nodulation. J. Bacteriol., 2006, 188: 1943-1949 (doi: 10.1128/JB.188.5.1943-1949.2006).

9. Amarger N., Lobreau J.P. Quantitative study of nodulation competitiveness in Rhizobium strains. Appl. Environ. Microbiol., 1982, 44(3): 583-588.

10. Beattie G.A., Clayton M.C., Handelsman J. Quantitative Comparison of the laboratory and field competitiveness of Rhizobium leguminosarum biovar phaseoli. Appl. Environ. Microbiol., 1989, 55(11): 2755-2761.

11. Provorov N.A., Vorob'e v N.I. Geneticheskie osnovy evolyutsii rastitel'no-mikrobnogo simbioza [Genetic basis for plant-microbe symbiosis evolution]. St. Petersburg, 2012.

12. K h m e l' I.A. Mikrobiologiya, 2006, 75(4): 457-464.

13. S h p a k ov A.O. Mikrobiologiya, 2009, 78(2): 163-175.

14. Conway B., Greenberg E. Quorum-Sensing signals and Quorum-Sensing genes in Burkholderia vietnamiensis. J. Bacteriol, 2002, 184: 1187-1191 (doi: 10.1128/jb.184.4.1187-1191.2002).

15. Daniels R., De Vos D.E., Desair J., Raedschelders G., Luyten E., Rosemeyer V., Verreth C., Schoeters E., Vanderleyden J., Michiels J. 
The cin Quorum-Sensing locus of Rhizobium etli CNPAF 512 affects growth and symbiotic nitrogen fixation. J. Biol. Chem., 2002, 277: 462-468 (doi: 10.1074/jbc.M106655200).

16. Koutsoudis M.D., Tsaltas D., M inogue T.D., Von Bodman S.B. Quorum-Sensing regulation governs bacterial adhesion, biofilm development, and host colonization in Pantoea stewartii subspecies stewartii. PNAS, 2006, 103: 5983-5988 (doi: 10.1073/pnas.0509860103).

17. Vorob'ev N.I., S e me nov A.M., Shatalov A.A., Van B rugge n A.Kh.K., S vi ri d o v a O.V. Izvestiya Samarskogo NTS RAN, 2009, 11(7): 1620-1624.

18. Schluter J.P., Czuppon P., S chauer O., Pfaffelhuber P., McIntosh M., $\mathrm{B} \mathrm{e} \mathrm{c} \mathrm{k} \mathrm{e} \mathrm{r} \mathrm{A.} \mathrm{Classification} \mathrm{of} \mathrm{phenotypic} \mathrm{subpopulations} \mathrm{in} \mathrm{isogenic} \mathrm{bacterial} \mathrm{cultures} \mathrm{by}$ triple promoter probing at single cell level. J. Biotechnol., 2015, 198: 3-14 (doi: 10.1016/j.jbiotec.2015.01.021).

19. Provorov N.A., Onishchuk O.P., Yurgel' S.N., Kurchak O.N., Chizhevskay a E.P., Vorob'ev N.I., Z at ov sk y a T.V., S i m a rov B.V. Genetika, 2014, 50(11): 1273-1285.

20. Braeken K., Daniels R., Ndayizeye M., Vanderleyden J., Michiels J. Quorum Sensing in bacteria-plant interactions. In: Molecular mechanisms of plant and microbe coexistence. Berlin, Heidelberg, Springer-Verlag, 2008: 265-289 (ISBN 978-3-540-75574-6) (doi: 10.1007/978-3-540-75575-3). 